\title{
Assimilation of SMOS L-band Wind Speeds: Impact on Met Office Global NWP and Tropical Cyclone Predictions
}

\author{
Cotton J. ${ }^{1,{ }^{*}}$, Francis P. ${ }^{1}$, Heming J. ${ }^{1}$, Forsythe M. ${ }^{1}$, Reul Nicolas ${ }^{2}$, Donlon C. ${ }^{3}$
}

${ }^{1}$ Met Office, FitzRoy Road; Exeter ,United Kingdom

${ }^{2}$ Laboratoire d'Océanographie Spatial, Institut Français de Recherche pour l'Exploitation de la Mer

(IFREMER), La Seyne-sur Mer, France

${ }^{3}$ European Space Agency, ESTEC, Earth Observation Programme Directorate, Keplerlaan 1; 2200 AG Noordwijk, The Netherlands

* Corresponding author : J. Cotton, email address : james.cotton@metoffice.gov.uk

\begin{abstract}
:
A new generation of L-band sensors, such as ESA's Soil Moisture Ocean Salinity (SMOS) mission, have the capability to provide information on the ocean-surface wind speed under high wind and rain conditions. In this study we evaluate the use of SMOS wind speeds within Met Office numerical weather prediction (NWP). Observation minus model background (O-B) departure statistics are used to investigate SMOS error characteristics, quality flags, and develop a quality control method. Observation errors and spatial correlation distances are estimated using a statistical method. Observing system experiments are performed to diagnose the impact of SMOS on NWP forecasts and analyses, including tropical cyclone (TC) predictions.

The quality of SMOS retrievals appears reduced in the presence of sea ice, strong river plumes, and radio-frequency interference (RFI) contamination. SMOS wind retrievals have reduced sensitivity at lowmoderate winds speeds. Above $15 \mathrm{~ms}-1$, SMOS winds tend to be faster than the model and have higher O-B variance compared to scatterometer winds from ASCAT. Above $30 \mathrm{~m} / \mathrm{s}$ RMS errors from SMOS are smaller than ASCAT. The impact of SMOS on TC predictions is sensitive to the use of the Met Office TC Central Pressure Initialisation Scheme (TCCPIS) which is confirmed to have a large, beneficial impact on intensity predictions. The assimilation of SMOS results in a small increase in TC intensity leading to a reduction in pressure/wind errors in the analysis and short-range forecasts, but cannot replicate the impact from the TCCPIS. The spatial resolution of SMOS is a clear limitation for analysing TC structure. In the case of Hurricane Kilo, the analysed and short-range forecast central pressures are closer to best-track when the storm radius is large and the eye is resolved. The challenge is to extract the useful information on intensity whilst preserving storm structure.
\end{abstract}

Keywords : SMOS, L-band, wind speed, data assimilation, tropical cyclones, NWP 


\section{Introduction}

Ocean surface wind measurements are an important component of the global observing system and are routinely assimilated in numerical weather prediction (NWP) models. Over the open ocean, satellite retrievals play a crucial role since they are able to provide nearglobal coverage in a relatively short space of time. Full wind vector information (i.e. speed and direction) can be inferred from 'active' microwave radar instruments known as scatterometers. Operating in the microwave region, typically between 5-14 GHz, scatterometers measure the returned signal or backscatter from the surface and the ocean backscatter response is sensitive to the near-surface wind vector. The current Met Office scatterometer assimilation (as of the start of 2017) consists of the C-band Advanced Scatterometer (ASCAT) instruments on-board the Metop-A (Keogh and Candy, 2008) and Metop-B satellites (Cotton, 2013). Surface wind vectors can also be retrieved using passive microwave observations in rain-free conditions and observations from the WindSat polarimetric radiometer are also assimilated (Candy et al., 2009).

In Met Office NWP scatterometer winds are used between 2-25 ms ${ }^{-1}$ which is the dynamic range over which the data are found to be most accurate compared to model forecasts. At very low wind speeds the variation in directional errors is large, whilst speed biases increase for high wind speeds (e.g. Bentamy et al., 2008; Soisuvarn et al., 2013). At shorter wavelengths, $\mathrm{Ku}$-Band instruments are sensitive to contamination from rain (e.g. Portabella and Stoffelen, 2001) precluding their use in areas of heavy precipitation. Now a new generation of microwave radiometers operating in the L-band $(1.4 \mathrm{GHz})$ are being used to estimate ocean surface wind speeds under extreme wind/rain conditions such as those found 
in tropical cyclones. These include the European Space Agency Soil Moisture and Ocean Salinity (SMOS) mission (Barre et al., 2008; McMullan et al., 2008) and the NASA developed Soil Moisture Active Passive (SMAP) mission (Meissner et al., 2017). SMOS carries the MIRAS instrument, an interferometric L-band radiometer operating at $1.4 \mathrm{GHz}$ (21 cm wavelength) consisting of 69 antenna receivers distributed over a Y-shaped antenna. The cross correlation of observations from all possible receiver pair combinations provides a two-dimensional brightness temperature $\left(T_{b}\right)$ image resulting in a swath around $1000 \mathrm{~km}$ across and average pixel size $\sim 43 \mathrm{~km}$. One of the benefits of L-band is that absorption by rain is significantly less than at higher frequencies. However, although SMOS operates in a protected band, contamination by Radio-Frequency Interference (RFI) is a significant issue (see Oliva et al., 2016) as SMOS does not feature any on-board RFI filters. The capability of SMOS to retrieve surface wind speeds in tropical cyclones was first demonstrated in Reul et al. (2012). It is found that the brightness temperature signature of the ocean is strongly dependent on foam coverage and thickness from whitecaps and streaks which lead to a 'whitening' of the sea surface. The foam-induced brightness temperature contrasts observed by SMOS have been related to the ocean surface wind speed using a quadratic geophysical model function (GMF). An improved GMF proposed by Reul et al. (2016) has been tuned using collocated Stepped-Frequency Microwave Radiometer (SFMR) aircraft winds and H*WIND analyses (Powell et al., 1998). A global database of wind speeds has been created covering the lifetime of the SMOS mission as part of the ESA SMOS+STORMS project (http://www.smosstorm.org/). Winds are oversampled on a $15 \mathrm{~km}$ grid and retrieved wind speeds are corrected for large-scale latitudinal biases towards model winds from the European Centre for Medium-Range Weather Forecasts (ECMWF) using a $10^{\circ}$ filter applied to the across-track averaged winds. 
In this paper we investigate the use of L-band wind speeds from SMOS within NWP. In Section 2 we examine the effectiveness of the supplied quality control flags and describe the background check used to remove cases of gross error. In Section 3 we assess the information content and error characteristics of the SMOS wind observations through comparison to short range NWP forecasts. The method used to assimilate surface wind speeds in the Met Office variational analysis is described in the appendix in Section 8. SMOS observation errors and spatial correlation distances are estimated using a statistical method in Section 4. Lastly in Section 5 we present a set of observing system experiments designed to evaluate the impact of SMOS on NWP forecasts and analyses, and in particular for tropical cyclone prediction.

Met Office tropical cyclone (TC) forecasts have shown significant improvement in recent years (Heming, 2016). Upgrades to the model dynamics, physics, and horizontal resolution in 2014 led to a positive impact on both track and intensity errors. A new TC Central Pressure Initialisation Scheme (TCCPIS) introduced in 2015 reduced intensity errors in the analysis and at short lead times, and also reduced track errors by $6 \%$. The initialisation scheme involves the assimilation of central pressure estimates provided by TC warning centres around the world. These are available at 3 or 6-hourly intervals and are interpolated to produce hourly estimates for assimilation. Although the TCCPIS was found to improve intensities, a weak bias remains in the analysis and at short lead times, e.g. see Figure 17 of Heming (2016). As the intensity bias is found to reduce with forecast lead time it is believed that improved data assimilation methods and observations are needed to better analyse TCs and further improve forecasts. 


\section{Quality flags and background check}

The SMOS level 2 wind speed product includes several data quality flags to assist in screening for observations that are less reliable. In this section we consider the six flags that are most likely to be useful indicators of wind speed quality: 1) distance to coast $\leq 150 \mathrm{~km} ; 4$ ) temporal standard deviation of sea surface salinity (SSS) $>0.8$ PSS; 5) sea surface temperature $\left.(\mathrm{SST}) \leq 0^{\circ} \mathrm{C} ; 7\right)$ moderate RFI probability $\left.\left(0<\mathrm{P}_{\mathrm{RFI}} \leq 25 \%\right) ; 8\right)$ high $\mathrm{RFI}$ probability $\left(\mathrm{P}_{\mathrm{RFI}}>25 \%\right)$; 9) pixel multi-angular variability of $T_{\mathrm{b}}>5 \mathrm{~K}$. To characterise the quality flags we use the mean and standard deviation (STDV) of the wind speed difference between SMOS and the Met Office model forecast as a quality indicator. Table 1 shows observation minus background (O-B) departure statistics partitioned by each of the quality flags. We see that around $14 \%$ of data have at least one of the quality flags activated, with the remaining $86 \%$ un-flagged. Comparing the statistics we see that all six flags are useful indicators of data quality to some degree, as correlations are lower and standard deviations more than $0.5 \mathrm{~ms}^{-1}$ larger than the un-flagged data. Flag 9 (multi-angle $T_{\mathrm{b}}$ variability) discriminates the poorest quality data that show high STDV and a large positive bias. Data occurring in areas of low SST (flag 5) also present a high level of variability with STDV exceeding $4 \mathrm{~ms}^{-1}$. The moderate probability of RFI contamination flag (flag 7) is the most frequently activated (4\%) and shows the least skill at discriminating poor-quality data. Table 1 also presents (in parenthesis) the percentage of data flagged when we only consider SMOS wind speeds exceeding $10 \mathrm{~ms}^{-1}$. When we remove the low wind speed data the percentage of un-flagged data increases to almost $89 \%$ and the total proportion of data flagged for RFI decreases from $5.8 \%$ to $2.4 \%$. This suggests that RFI flagging is less likely to affect the high wind speed regions which are of most interest for the application of SMOS. 
In NWP assimilation systems observations are treated as being un-biased. Whilst bias correction schemes (e.g. Stoffelen and Vogelzang, 2015) should correct small systematic errors it is also necessary to detect observations that contain large, gross errors compared to the model. In the assimilation scheme this is referred to as the 'background check' and flags observations so that they are not used in the analysis. The Met Office background check is based on the Bayesian probability theory approach of Lorenc and Hammon (1988) and set in a wider context by Ingleby and Lorenc (1993). For SMOS we set the background check input parameters such that the background check departure limits are fairly relaxed, e.g. for a background error of $3 \mathrm{~ms}^{-1}$ and an observation error of $2.5 \mathrm{~ms}^{-1}$ the departure limit is $14 \mathrm{~ms}^{-1}$. Table 1 confirms that the SMOS background check only removes a further $\sim 0.1 \%$ of data after the quality control flags have been applied and results in a small reduction in O-B standard deviation.

\section{Comparison with model background}

A standard diagnostic used at NWP centres is the comparison of the observed value with model estimates from a recent short-range forecast, interpolated to the observation location and time. This is the observation minus background departure, or O-B. In this section we examine SMOS wind speed O-B statistics in order to better understand the error characteristics of the data.

\subsection{2-D histograms}

A comparison of SMOS wind speeds with collocated $10 \mathrm{~m}$ model wind speeds is given in Figure 1 for a 10-day period in August 2014. If we first consider all data (Figure 1a), the twodimensional histogram shows a large cloud of points at model speeds less than $15 \mathrm{~ms}^{-1}$ for 
which SMOS wind speeds are substantially larger, often exceeding $40 \mathrm{~ms}^{-1}$. It is also evident that at lower wind speeds there is an increase in the spread of the distribution about the $1: 1$ line. The reduced sensitivity of SMOS at lower wind speeds is expected as surface foam layers only emit L-band radiation if they are thicker than $10 \mathrm{~cm}$ and these generally start to appear for wind speeds in excess of $\sim 12 \mathrm{~ms}^{-1}$ (Reul et al., 2012). For speeds above $10 \mathrm{~ms}^{-1}$ the line of mean fit (dashed line) shows that SMOS is on average faster than the model and the difference increases with wind speed. Figure $1 \mathrm{~b}$ shows the subset of data that have quality flags $1,4,5,7,8$, or 9 activated. Individual plots for each flag (not shown) reveal that the gross departures at low model speeds are primarily associated with low SST values (flag 5), but also data with medium/high probability of RFI contamination (flags 7 and 8). Once the flagged data has been removed as in Figure 1c the cloud of data with large positive bias reduces in density and extent, but some bias remains for model speeds less than $10 \mathrm{~ms}^{-1}$. Figure 1d demonstrates the impact of applying the background check on top of the quality flag check. It can be seen that the background check is fairly relaxed and only removes cases of gross error. Importantly it can be seen that the background check does not unduly affect SMOS observations for which the model wind speed is high e.g. above $30 \mathrm{~ms}^{-1}$.

\subsection{Wind speed statistics}

SMOS departure statistics binned by model background wind speed are plotted in Figure 2 and summarised in Table 2. O-B statistics for the ASCAT-B scatterometer are also shown for comparison. ASCAT data are from the $25 \mathrm{~km}$ product produced by the European Organisation for the Exploitation of Meteorological Satellites (EUMETSAT) Ocean and Sea Ice Satellite Application Facility (OSI SAF). The results presented here are global statistics i.e. the sensors have not been collocated with each other. As expected, for low-moderate wind speeds SMOS has a much larger level of variance in O-B. Below $15 \mathrm{~ms}^{-1}$, ASCAT standard 
deviation O-B is just $1.16 \mathrm{~ms}^{-1}$ but SMOS is more than double at $2.44 \mathrm{~ms}^{-1}$. The noise level for SMOS is higher than would be expected from SMAP, for example, mainly due to increased radiometric noise. Above $15 \mathrm{~ms}^{-1}$ the trend in mean $\mathrm{O}-\mathrm{B}$ is quite different for the two sensors; SMOS having an increasing positive bias $\left(+2 \mathrm{~ms}^{-1}\right.$ at $\left.30-35 \mathrm{~ms}^{-1}\right)$, and ASCAT an increasing negative bias $\left(-4 \mathrm{~ms}^{-1}\right)$ as we move to higher model speeds. For the handful of model winds above $35 \mathrm{~ms}^{-1}$, SMOS shows good agreement, whilst ASCAT is biased low by 8 $\mathrm{ms}^{-1}$. ASCAT standard deviation O-B remains much lower than SMOS at all wind speeds, but the RMS difference for ASCAT grows rapidly above $30 \mathrm{~m} / \mathrm{s}$ due to the strong negative bias. It has been demonstrated for SMOS (Reul et al., 2016) and SMAP (Meissner et al., 2017) that the wind-induced emissivity signal at L-band does not saturate even at very high winds.

\subsection{Geographical distribution}

The spatial distribution of SMOS wind speed departures are shown in Figure 3, for all data (left column) and after the flag and background checks have been applied (right column). Whilst mean speed bias is near-zero for large parts of the world's ocean there are several problem areas that can be identified as having a large positive bias (Figure 3a), and increased standard deviation (Figure 3c). The quality of SMOS retrievals appears reduced in the presence of; i) sea ice contamination in the Southern Ocean near Antarctica, ii) strong river plumes, e.g. Amazon, iii) RFI contamination, particularly in the Arabian Sea, N.E. Atlantic, S. and E. Asian coastal zones, and some remote islands e.g. $171^{\circ} \mathrm{W}, 12^{\circ} \mathrm{N}$. Strong river plumes can degrade the retrieved wind speed since the sea surface salinity (SSS) fields used to estimate the flat sea surface emission are a 7-day running mean (Reul et. al, 2016). Therefore the SSS flag (4) is designed to screen areas such as river plumes that exhibit large SSS variability on time scales less than a week. The relationship between sea ice thickness and SMOS brightness temperature has been demonstrated by Kaleschke et al. (2012). Sea ice 
being much brighter than open sea water at L-band and SMOS being an interferometer, the brightness image of such high-gradient zones reconstructed through an Inverse Fourier Transform is affected by Gibbs-like phenomena. Properly correcting for these effects is an area of on-going research but the SMOS SST flag attempts to screen these contaminated data using a threshold of $273 \mathrm{~K}$. Applying the quality flag checks does a good job at screening for biases associated with sea ice and river plumes, and partially mitigates the presence of RFI contamination. The addition of the background check (Figure $3 \mathrm{~b}$ and $\mathrm{d}$ ) helps to clean up residual RFI contamination; however some remains e.g. in the Arabian Sea. For persistent problem areas a spatial blacklist should be considered.

\subsection{Across-track distance}

SMOS level 2 wind speeds also include a dimensionless measure of the satellite across-track distance (number between -1 and 1) and we convert this to a relative measure of the swath position. The variation in O-B with satellite swath position can be seen in Figure 4 together with a histogram of the number of winds in each bin. The plot shows that there is little modulation of the mean bias across the swath with values largely within $+/-0.5 \mathrm{~ms}^{-1}$. The standard deviation shows increasing variance in O-B towards the swath edges. This degradation in quality can be explained by the SMOS viewing geometry, where the field of view is a distorted hexagon shape with curved sides (see Figure 1 of Kerr et al., 2001). The geometry results in fewer brightness temperature $T_{\mathrm{b}}$ measurements for positions at the edge of the swath and less variety of incidence angles (Figure 3 in Yin et al., 2014). The spatial resolution of the reconstructed $T_{\mathrm{b}}$ data and the radiometric accuracy also vary within the field of view. One option to account for the degradation in wind speed at the swath edges would be to only accept data from the central part of the swath; however this would seriously reduce the spatial coverage. A better approach would be to modulate the assigned observation error 
so that data in the swath edges are assigned larger errors and given reduced weight in the analysis.

\section{Observation errors and spatial correlations}

An accurate estimation of the SMOS observation error is important to ensure that the observations are correctly weighted relative to the model background. The two main components of observation error are systematic errors (biases) and random errors. The assimilation method assumes no systematic errors, whilst random errors are represented through the observation error covariance matrix $R$ in Appendix Eq. (1)Error! Reference source not found.. SMOS wind speeds are a spatial average over a grid-area of $\sim 40 \mathrm{~km}$ so there will be representativeness error contributions from sub-grid wind variability as the observation operator described in Appendix Eq. (3) Error! Reference source not found. assumes the wind to be a point observation. The assimilation assumes observation errors to be uncorrelated and to mitigate for this we use spatial thinning to ensure a minimum separation of observations in space. Observation error covariances can be estimated using statistical methods such as that used by Desroziers et al. (2005). Here we apply the Desrozier diagnostic on a sample of 7 days of innovations (O-Bs) and residuals (O-As) following the method outlined in Weston et al. (2014). The diagnosed error covariances and correlations are shown in Figure 5 at intervals of $12.5 \mathrm{~km}$. SMOS error standard deviations are estimated to be $1.35 \mathrm{~ms}^{-1}$ and correlations are well below 0.2 for a separation distance of $50 \mathrm{~km}$. The direct use of the diagnosed error in the assimilation would likely give too much weight to the observations. Therefore an inflation factor of $5 / 3$ is used to give a final estimate of $2.25 \mathrm{~ms}^{-1}$ for the SMOS observation error. The inflation factor is based on the ratio of operational/diagnosed errors for ASCAT and should ensure a suitable weighting between the two different observation types. ASCAT has an assigned observation error of $2.0 \mathrm{~ms}^{-1}$ in $u / v$ 
wind components and so the corresponding wind speed error will be even smaller. Hence for the wind speed range where they are both used (around 15-25 m/s), more weight will be given to ASCAT than SMOS which seems appropriate given the results in Figure 2. Above $25 \mathrm{~m} / \mathrm{s}$ ASCAT winds are not currently assimilated due to the strong negative wind speed OB described in Section 3.2.

\section{Impact experiments}

A set of Observing System Experiments (OSEs) are used to determine the impact of assimilating SMOS wind speeds. In each time period a control experiment is run which closely matches the configuration that became the operational suite (OS) in March 2016 (OS37). Unified Model (UM) system (Davies et al., 2005; Walters et al., 2014) forecasts are run at a reduced resolution of $\mathrm{N} 320(\sim 40 \mathrm{~km}$ in mid-latitudes) using 70 vertical levels and a model top around $80 \mathrm{~km}$. The data assimilation scheme is incremental $4 \mathrm{D}-\mathrm{Var}$ run at a resolution of N216 ( 60 km) with N108 pre-conditioning. Background errors are 'hybrid' method, combining standard climatological covariances with errors of the day information provided by the operational global ensemble (Clayton et al., 2013). Analyses are created 4 times per day at 00/06/12/18 UTC using 6 hour assimilation windows. The configuration also includes variational bias correction (VarBC) of satellite radiance data (Cameron and Bell, 2016) and biases are spun-up for around 6 days prior to starting the experiments. The list of observation types assimilated in the control experiment are given in Table 3. Note that scatterometer winds are only used in the range $2-25 \mathrm{~ms}^{-1}$.

As described in Section 1, the Met Office has seen a large benefit from the assimilation of central pressure estimates from tropical cyclone warning centres - the TCCPIS. Therefore to 
assess the sensitivity of the impact of SMOS on tropical cyclones errors, experiments have been performed both with and without the TCCPIS.

Unless otherwise stated, the use of SMOS in the trial experiments is summarised as follows:

- $\quad$ Remove data with quality flags $1,4,5,7,8$, or 9 activated

- Use an internal OSTIA threshold of 272.5K (as additional check to Flag 5)

- Apply model background check

- Use $\max / \min$ latitude bounds of $78^{\circ} \mathrm{N} / 72^{\circ} \mathrm{S}$

- Spatial blacklist areas with persistent RFI: North Sea, Baltic Sea, Mediterranean, Red Sea and Gulf of Aden, Persian Gulf, Arabian Sea (west of Oman), Bay of Bengal, Yellow Sea and East China Sea, Sea of Japan, and regions near Samoa and the Windward Islands.

- Assigned observation error of $2.25 \mathrm{~ms}^{-1}$

- Spatial thinning $80 \mathrm{~km}$

- Minimum SMOS and background wind speed of $15 \mathrm{~ms}^{-1}$

\subsection{August-October 2014 season}

The aim of this trial period was to capture as many tropical cyclones as possible. The East Pacific (here defined to be bounded by $180^{\circ} \mathrm{W}$ to the west) was exceptionally active in 2014 with 22 named storms, of which 16 became hurricanes with 9 achieving major (category 3 or above on the Saffir-Simpson Hurricane Wind Scale) hurricane status (http://www.nhc.noaa.gov/data/tcr/; http://www.prh.noaa.gov/cphc/summaries/; accessed 10 May 2017). West Pacific activity (as measured by The Joint Typhoon Warning Center; JTWC) was slightly below average with 21 tropical storms, including 11 typhoons of which 7 reached category 3 or more (http://www.usno.navy.mil/JTWC/annual-tropical-cyclone- 
reports; accessed 10 May 2017). The North Atlantic was below average with 8 named storms, including 6 hurricanes of which 2 were major. Trial dates were from 1 August 2014 to 20 October 2014 and the list of experiments is shown in Table 4. A control (Control+TCP) and SMOS trial (SMOS+TCP) were run with the TCCPIS active. These same experiments were then repeated with the TCCPIS switched off (ControlNoTCP and SMOSNoTCP). A 'stretch' SMOS experiment (StretchNoTCP) used the data more aggressively: the background wind speed threshold was removed, the background check was loosened slightly, and the moderate RFI check was removed. The latter change was tested due to instances in the N.W. Pacific basin where storm intercepts by SMOS were flagged by the quality control even though the wind speeds showed no evidence of contamination, e.g. Typhoon Halong. After 31 days of trialling the StretchNoTCP trial was performing better than SMOSNoTCP and so only the stretch trial was run through to completion.

The spatial coverage and density of SMOS observations used in analyses for August 2014 can be seen in Figure 6. The mean number of observations used per 6-hour cycle is 344 for the SMOS+TCP experiment and 661 for the StretchNoTCP experiment. The number of SMOS winds used in the analysis is small compared to the $\sim 11,000$ used for each ASCAT instrument. The greatest numbers of winds are located in the southern hemisphere midlatitudes, whilst the storm track regions are also clearly identified. The increased coverage in the stretch experiment results from removing the background wind speed threshold.

To evaluate the impact of SMOS we first compare mean changes to the global atmospheric analyses relative to the respective control experiments. For experiment SMOS+TCP we find the changes in mean analysis are very small (not shown), but for the StretchNoTCP experiment the increased data coverage results in larger differences. Figure 7 shows the 
impact on the zonal wind analyses near the surface for the stretch experiment. This shows the addition of SMOS increases the strength of the mid-latitude westerlies in the South Indian Ocean as well as the Somali Jet. Forecasts are validated with quality controlled observations or model analyses valid at the same time. Figure 8 shows 48 hour forecasts of $1000 \mathrm{hPa}$ geopotential height verified against own analyses. A reduction in RMS errors can be seen in the Indian Ocean south of Australia, downstream from the change in zonal wind analysis from Figure 7. Other impacts, both positive and some negative, can be seen in the storm-track regions of the N.W. Pacific, N. Atlantic, and E. Pacific. The large, beneficial impact near Newfoundland originates from two 48 hour forecasts made on 27 August 1200 UTC and 28 August 0000 UTC and coincides with the position of Hurricane Cristobal.

An important metric for assessing forecast impact at the Met Office is the so-called NWP Index; a weighted skill score combining improvements in forecast skill for a subset of atmospheric parameters. These are pressure at mean sea-level (PMSL), geopotential height at $500 \mathrm{hPa}$, and winds at $250 / 850 \mathrm{hPa}$. The changes in forecast RMS error for the NWP Index parameters are given in Figure 9 and Figure 10 for experiments SMOS+TCP and StretchNoTCP respectively versus their control experiments. The statistics are separated by latitude band and forecast lead time, with negative RMS differences representing an improvement in forecast accuracy as a result of assimilating SMOS data. The overall change in NWP Index scores are given in Table 4. For a trial length of 80 days any impact of less than $\sim 0.2 \%$ on the NWP Index should be considered neutral at the $95 \%$ significance level (extrapolated from Weston, 2014).

When SMOS data are assimilated with the TCCPIS (Figure 9) the impact on forecasts in the northern hemisphere $(\mathrm{NH})$ is rather neutral. The tropical winds at $850 \mathrm{hPa}$ show small 
reductions in forecast error versus own and independent ECMWF analyses which are statistically significant at the $95 \%$ level. Impacts in the southern hemisphere (SH) whilst still rather neutral are slightly on the negative side versus analyses, and for PMSL versus observations.

When the TCCPIS is removed and SMOS is used more aggressively the impact on global forecasts remains small, but is more beneficial in the extra-tropics (Figure 10). This is reflected in the improved NWP Index scores shown in Table 4 and the impact of +0.35 against own analyses is statistically significant at the $95 \%$ level. Results are generally consistent when verified against observations and analyses, and the improvement in NH 500 hPa geopotential height and PMSL is statistically significant at $\mathrm{T}+60 / 72$ hours. Small increases in error are evident for short-range forecasts e.g. tropical wind $850 \mathrm{hPa}$ and $\mathrm{SH}$ PMSL. The benefit on tropical winds at $850 \mathrm{hPa}$ has been lost.

When new observations are added to the assimilation, it is important that the fit of the model background (i.e. the 6-hour forecast) to the existing set of observations is not degraded in comparison to the control experiment. For both SMOS experiments the change in background fit to other observations is generally small. For experiment StretchNoTCP scatterometer zonal and meridional standard deviation $\mathrm{O}-\mathrm{B}$ are higher by $0.4 \%$ and $0.2 \%$ respectively. For experiment SMOS+TCP the scatterometer O-B differences are less than $0.1 \%$. It appears that using SMOS more aggressively and in particular removing the check on the background wind speed has a small detrimental impact on the scatterometer fit.

The August-October trial season captured 28 tropical cyclones (TCs) at tropical storm strength and above: 8 in the North West Pacific (west of $180^{\circ} \mathrm{W}$ ), 13 in the North East Pacific 
(east of $\left.180^{\circ} \mathrm{W}\right), 6$ in the North Atlantic, and 1 in the North Indian Ocean. The impact of SMOS on TC forecasts is evaluated through comparison to 'best-track' data obtained from IBTrACS (International Best Track Archive for Climate Stewardship) (Knapp et al., 2010). The database includes 6-hourly observed storm position and maximum one-minute sustained wind speed information. Over 2,000 TC forecasts are verified in this period and details of the tracking and verification method can be found in Heming (2017). Table 5 summarises the mean TC intensity and track verification for the SMOS trials, with and without the TCCPIS. The table shows the difference in mean relative vorticity (RV) at $850 \mathrm{hPa}$, maximum $10 \mathrm{~m}$ wind and minimum mean sea level pressure (MSLP) between the trial and the control experiments. Also given are the corresponding changes in the wind and MSLP mean absolute errors (MAE) as measured against best-track, and the change in track skill measured against climatology and persistence (CLIPER; Neumann 1972) between the trial and control experiments. These changes are discussed further below.

Figure 11 compares storm intensity for the two SMOS trials and their respective controls in terms of RV. Comparing results for the controls (shown in solid lines) we confirm the TCCPIS has a very large impact and increases intensity in the analysis $(+24 \% \mathrm{RV})$ and shortrange forecasts which persists out to day 5. When SMOS is added on a no-TCCPIS baseline there is an increase in intensity of around 5\% in the analysis, and differences are observed out to around day 3 . When the TCCPIS is active, SMOS acts to reduce intensity slightly in the first 48 hours. Are the changes in wind and MSLP shown in Table 5 beneficial or detrimental to TC intensity errors? Figure 12 shows that for the no-TCCPIS baseline control, TC intensity in the analysis is too weak compared to best-track. The bias increases in the first 48 hours as the model is initially too slow to spin up TC's before decreasing at longer lead times. The increased intensity from the TCCPIS results in smaller biases in central pressure and $10 \mathrm{~m}$ 
winds (compare solid lines). Similarly the addition of SMOS, without the TCCPIS, gives a small reduction in intensity biases in the analysis and at short lead times. Table 5 shows that with SMOS, MAE are reduced by 0.8 knots / $0.4 \mathrm{mb}$ in the analysis and by 0.4 knots $/ 0.2 \mathrm{mb}$ when averaged across all forecast lead times.

The impact of SMOS on TC track errors with and without the TCCPIS is shown in Figure 13. In both cases there are small improvements in $\mathrm{TC}$ positions in the analysis. When the TCCPIS is active, mean DPE are $2.6 \%$ lower in the analysis and $1.1 \%$ lower when averaged over all forecast ranges. Both experiments show an increase in DPE at short lead times. At longer lead times errors are reduced when the TCCPIS is used but increased in its absence. Model skill in predicting the track of TCs against CLIPER is calculated for forecasts out to day 3. Skill scores for the SMOS trials are around $1 \%$ lower on average due to the increase in track DPE for days 1-2.

\subsection{August - September 2015}

The 2015 East Pacific (east of $180^{\circ} \mathrm{W}$ ) hurricane season was exceptionally active producing 26 named storms, of which 16 became hurricanes, and 11 major hurricanes. Three major hurricanes, named Kilo, Ignacio and Jimena, were notable because on 29 August all three were category 4 hurricanes simultaneously. SMOS intercepted these storms fairly regularly during their lifetime (23 times between 27 August and 7 September). A one-month trial from 20 August 2015 to 20 September 2015 was chosen to evaluate the impact of SMOS on forecasts for Kilo, Ignacio and Jimena. A control (ControlNoTCP) and trial (StretchNoTCP) were run with the TCCPIS switched off to provide a cleaner comparison of TC results. As noted in Heming (2016) the central pressure data in the TCCPIS can be rejected from the assimilation in cases of rapidly deepening storms since these data must also pass a 
background quality control check on O-B central pressure. As a consequence TC intensity predictions can become sensitive to even small changes in the model background state across different experiments.

Verifying forecast errors against observations, own analysis and ECMWF analysis, the changes in the NWP Index are $+0.23(0.21 \%),+0.43(0.33 \%)$ and $+0.21(0.19 \%)$ respectively for the SMOS experiment compared to the control. For a 30-day trial any impact less than $0.4 \%$ can be considered neutral, which is the case for all three metrics here. As shown in Figure 14 changes in forecast RMS errors are mostly beneficial, particularly for SH forecasts against ECMWF and own analyses. For geopotential height at $500 \mathrm{hPa}$ the reductions in RMS error against ECMWF exceed $0.5 \%$ for lead times 36 hours and more, and are statistically significant for days 1-3.

There were a total of 18 TCs during the 30-day trial period: 5 in the North West Pacific (west of $\left.180^{\circ} \mathrm{W}\right), 7$ in the North East Pacific (east of $180^{\circ} \mathrm{W}$ ), and 6 in the North Atlantic. This gave a total of 181 analyses and 1127 TC forecasts to verify. Table 6 summarises the mean TC intensity and track verification for the control and SMOS trial. Considering all storms TC intensity is higher in the SMOS trial. In the analyses RV is increased by $6 \%$ and $10 \mathrm{~m}$ maximum winds are increased by $3 \%$, resulting in lower central pressures. The increased intensity leads to smaller analysis errors of $10 \mathrm{~m}$ winds and pressures of 1 knot and $0.6 \mathrm{mb}$ respectively. Forecast wind/pressure errors are reduced out to day 2 in the trial (not shown). The impact on TC track is rather mixed. Direct positional errors are reduced on average by $1.9 \%$ in the analysis, but are $1.3 \%$ larger in forecasts when averaged across all lead times. Similar to the 2014 experiments the track errors are larger at days 1 and 2 which lead to lower skill scores versus CLIPER.

This article is protected by copyright. All rights reserved. 
The individual storm statistics in Table 6 are less significant as fewer cases are verified, especially for long lead times. Nevertheless, Ignacio, Jimena and Kilo all show reduced intensity errors in the SMOS trials resulting from stronger $10 \mathrm{~m}$ winds and lower central pressures. In particular analysed 10m wind MAE's are reduced by 1.6 knots for Jimena and 1.5 knots for Kilo. Impacts on TC track errors for theses storms however are generally mixed or non-beneficial. For Ignacio, positional errors are $9 \%$ lower in the analysis, $2 \%$ lower at day 1, but $8 \%$ larger at days 2 and 3. For Kilo the reverse trend occurs as track errors are degraded at analysis and day 1 but improved for days 2 and 3.

We can also monitor the accuracy of the TC intensity through the storm lifecycle as shown for Kilo in Figure 15. Kilo was a very long-lived storm and was intercepted by SMOS numerous times during its 22-day lifespan. Kilo experienced two intensification stages; an initial rapid intensification into a major hurricane on 29 August, and a re-intensification to a category 1/2 typhoon on 5 September (after crossing the International Date Line). Figure 15 shows that neither the control nor SMOS trial captured the rapid intensification of the storm. For the later re-intensification period we can observe some differences between the experiments. Between 5 Sept 0000 UTC and 8 Sept 1200 UTC analysed and short-range forecast central pressures are closer to best-track for the SMOS experiment. Both do a reasonable job at forecasting the re-intensification stage from longer lead-times but subsequent forecasts lead to an over-intensification of the storm when it should be weakening according to best-track. Similar trends are seen for the equivalent plot of $10 \mathrm{~m}$ wind predictions. Reul et al. (2017) compared the temporal evolution of wind radii from an ensemble of SMOS, SMAP and AMSR-2 overpasses for Kilo and found the 50/60 knot wind radii were overestimated during the decaying phase of the storm. The intensification stage 
around 30 August, seen as a peak in the wind radii, was also underestimated by the SMOS passes on 29/30 August.

Figure 16 and Figure 17 look at the intensification cases in more detail for both SMOS and model winds. In the rapid intensification stage the storm radius is compact and so the radial extent of SMOS observations greater than $15 \mathrm{~ms}^{-1}$ is small. Here the limitation in terms of spatial resolution is clear since the eye structure present in the model is not resolved by SMOS. The lack of an eye in the observations means the background check is activated leaving an annulus of observations to be assimilated around the storm. The analysis increment displayed in terms of the wind speed shows that the background check helps to preserve the overall storm structure whilst still extracting useful information on the storm intensity, strengthening the areas of maximum wind.

In the re-intensification stage shown in Figure 17 the storm is located farther north $\left(\sim 24^{\circ} \mathrm{N}\right)$ and the areal extend of SMOS winds $>15 \mathrm{~ms}^{-1}$ is much larger. The larger storm size enables SMOS to resolve a small eye structure that is slightly offset to the north and west relative to the model background position. The improved representation of the storm structure means that fewer observations are removed by the background check near the eye and likely results in the improved intensity compared to best-track. However as Typhoon Kilo decays we see that the intensity is overestimated in both the control and trial experiments.

\section{Conclusions and discussion}

The quality of SMOS wind retrievals appears reduced in the presence of sea ice contamination, strong river plumes, and RFI contamination. O-B statistics show the supplied quality flags have some skill in discriminating poorer quality retrievals but RFI remains an 
issue. Applying a model background check for gross wind speed errors is essential to help remove residual RFI contamination but some problems areas persist. RFI-flagged data is found to be less likely in high wind speed regions however instances of over-flagging have been observed in the N.W. Pacific basin, e.g. Typhoon Halong.

Comparison with model background wind confirms that SMOS retrievals have reduced sensitivity at low-moderate winds speeds. Above $15 \mathrm{~ms}^{-1}$ SMOS wind speeds are on average faster than the model background, and for a small number of model winds above $35 \mathrm{~ms}^{-1}$ SMOS shows good agreement. At high wind speeds ASCAT has an increasingly large negative bias and high RMS values, but lower standard deviation than SMOS. For SMOS we find there is little modulation of the mean bias across the swath but increased variance in O-B at swath edges. Observation error correlations are found to be small for separation distances greater than $50 \mathrm{~km}$, although a more conservative estimate of $80 \mathrm{~km}$ is used in the experiments. Some inflation of diagnosed observation errors is necessary to ensure suitable weighting relative to ASCAT (SMOS given less weight in the analysis).

Impact experiments for the different time periods (Aug-Oct 2014, Aug-Sep 2015) show the number of SMOS winds used in the assimilation is small, up to $\sim 700$ observations per 6-hour cycle (c.f. $\sim 11,000$ for a single ASCAT). SMOS data are only used at wind speeds above 15 $\mathrm{ms}^{-1}$ and so the largest proportion of data is in the mid-latitudes. The assimilation of SMOS acts to strengthen the mid-latitude westerlies in the S. Indian Ocean and the Somali Jet. When SMOS is used more aggressively we observe a small detrimental impact on the background forecast fit to scatterometers. 
The Met Office TCCPIS has a large, beneficial impact on TC intensity predictions. Without the TCCPIS, SMOS increases the analysed intensity of tropical cyclones by $5-6 \%$ and leads to a small reduction in pressure and wind errors in the analysis and short-range forecasts. When SMOS is assimilated on top of the TCCPIS there is a small reduction in intensity. The impact on TC track errors is rather mixed: positional errors are found to be smaller in the analysis but larger for short-range forecasts. In the case of rapidly deepening storms it is found that small differences in the background state of the experiments can lead to very large differences in the analysis (and future forecasts) due to the acceptance/rejection of central pressure data

For global forecast metrics, the addition of SMOS with the TCCPIS active results in small but statistically significant error reductions for tropical winds at $850 \mathrm{hPa}$ versus analyses. RMS errors are generally slightly larger in the southern hemisphere however. Without the TCCPIS, changes in forecast RMS scores are mostly beneficial in the extra-tropics with some significant error reductions at forecast lead times of 36-72 hours. However increases in forecast error are seen at short-range for PMSL in the southern hemisphere and $850 \mathrm{hPa}$ winds in the tropics.

Hurricanes Ignacio, Jimena and Kilo in the Eastern Pacific all show reduced intensity errors in the SMOS experiments. In the case of hurricane Kilo, both the control experiment and the SMOS trial fail to capture the initial rapid intensification of the storm. When the storm-radius is small SMOS is unable to resolve the eye structure present in the model. For the later reintensification stage the storm-radius is much larger, SMOS can resolve the eye structure and analysed and short-range forecast central pressures are closer to best-track in the SMOS experiment. 
As shown by the differing error characteristics of SMOS and ASCAT there is a need for better agreement between sensors at high wind speeds, otherwise we are attempting to pull the model in different directions. It is shown that the ASCAT wind speed scaling is far too low compared to the model (and SMOS). The SMOS spatial resolution is clearly a limiting factor for examining strong wind gradients. The challenge is to extract the useful information on intensity whilst preserving the storm structure. The current observation operator assumes the data to be a point measurement in space but for full high-resolution trials it may be beneficial to treat them as a spatial average. Modulating the observation errors as a function of swath position may also lead to a better treatment in the assimilation.

This study confirms the clear benefit of the TCCPIS in the current model configuration. It is perhaps not surprising that a single satellite, providing at most 1 or 2 intercepts per day, cannot match the impact of inserting pressures every hour at storm centre.

\section{Acknowledgements}

We acknowledge the support of the ESA Support To Science Element (STSE) program under the contract SMOS+STORMS Evolution, \#4000105171/12/I-BG.

\section{Appendix: Wind Speed Assimilation Method}

The aim of data assimilation is to combine, in an optimal way, prior information on the current state of the atmosphere (the model background) with updated information from a set of observations. The result is known as the analysis. The Met Office's data assimilation scheme uses a four-dimensional variational (4D-Var) method as described in Rawlins et al. 
(2007). This involves finding, by successive iterations, the atmospheric state which minimises a global cost function

$$
\begin{aligned}
J & =J_{\mathrm{b}}+J_{\mathrm{o}} \\
& =\frac{1}{2}\left(\mathbf{x}-\mathbf{x}_{\mathbf{b}}\right)^{T} \mathbf{B}^{-1}\left(\mathbf{x}-\mathbf{x}_{\mathbf{b}}\right)+\frac{1}{2}\{\mathbf{y}-H(\mathbf{x})\}^{T} \mathbf{R}^{-1}\{\mathbf{y}-H(\mathbf{x})\},
\end{aligned}
$$

where $J_{\mathrm{o}}$ is the observation cost term and $J_{\mathrm{b}}$ is the background cost term. Here $\mathbf{x}$ is the model state vector, $\mathbf{x}_{\mathrm{b}}$ the background state vector, $\mathbf{y}$ the vector of observations, $\mathbf{B}$ the background error covariance matrix, $\mathbf{R}$ the observation error covariance matrix, and $H$ the observation operator. The method for assimilating 10m winds speeds from SMOS is outlined below and largely follows the scheme previously used for Special Sensor Microwave Imager (SSM/I) winds (Ridley and Ballard, 2000).

\subsection{Cost function}

The observation cost in Eq. Error! Reference source not found.(1) is a sum of the contributions from each observation to be used in forming the analysis. Introducing a new type of observation requires the addition of a term to the observation cost function. For a surface wind speed observation $w s_{o}$ this is a quadratic of the deviation from the latest atmospheric state mapped into the observation space $w s_{m}$, inversely weighted by the estimated observation error variance $\sigma_{\mathrm{o}}^{2}$

$$
J_{\mathrm{wS}}=\frac{\left(w s_{\mathrm{m}}-w s_{\mathrm{o}}\right)^{2}}{\sigma_{\mathrm{o}}^{2}} .
$$

\subsection{Wind speed operator}

In Eq. (2) the model $10 \mathrm{~m}$ wind speed $w s_{\mathrm{m}}$ is mapped from the latest atmospheric state using the observation operator $H$. This can be fully non-linear or incremental using the tangent linear operator depending on the iteration. The full non-linear operator is 


$$
\begin{aligned}
w S_{\text {nonlin }} & =\sqrt{{u_{10}{ }^{2}+v_{10}{ }^{2}}^{2}}, \\
& =\sqrt{\left(u_{10 \mathrm{~b}}+u_{10}{ }^{\prime}\right)^{2}+\left(v_{10 \mathrm{~b}}+v_{10}\right)^{2}}
\end{aligned}
$$

where $u_{10 \mathrm{~b}}, v_{10 \mathrm{~b}}$ are the background $10 \mathrm{~m}$ wind components, $u_{10}{ }^{\prime}, v_{10}{ }^{\prime}$ are the analysis increments, and so the zonal and meridional wind components are given by

$$
u_{10}=u_{10 \mathrm{~b}}+u_{10}{ }^{\prime}, \quad v_{10}=v_{10 \mathrm{~b}}+v_{10}{ }^{\prime} .
$$

The linear operator is given through linearisation about the background values $u_{10 \mathrm{~b}}, v_{10 \mathrm{~b}}$

$$
w s_{\text {lin }}\left(u_{10}, v_{10}\right) \approx w S\left(u_{10 \mathrm{~b}}, v_{10 \mathrm{~b}}\right)+\left(\left.\frac{\partial w s}{\partial u_{10}}\right|_{u_{10 b}, v_{10 \mathrm{~b}}}\right)\left(u_{10}-u_{10 \mathrm{~b}}\right)+\left(\left.\frac{\partial w s}{\partial v_{10}}\right|_{u_{10 b}, v_{10 \mathrm{~b}}}\right)\left(v_{10}-v_{10 \mathrm{~b}}\right)
$$

where the gradients of the wind speed with respect to the $10 \mathrm{~m}$ wind components are

$$
\frac{\partial w s}{\partial u_{10}}=\frac{u_{10}}{w s}, \quad \frac{\partial w s}{\partial v_{10}}=\frac{v_{10}}{w s} .
$$

Using Eq. (4)Error! Reference source not found. and Eq. (6)Error! Reference source not found., the linear operator Eq. (5)Error! Reference source not found. becomes

$$
w S_{\text {lin }}\left(u_{10}, v_{10}\right) \approx w S_{10 \mathrm{~b}}+\left(\frac{u_{10 \mathrm{~b}}}{w S_{10 \mathrm{~b}}}\right) u_{10}{ }^{\prime}+\left(\frac{v_{10 \mathrm{~b}}}{w S_{10 \mathrm{~b}}}\right) v_{10}{ }^{\prime} .
$$

The gradients are not well-behaved as the wind speed approaches zero. To avoid this an additional term can be added to smoothly limit the wind speed to a minimum value, $s$

$$
w S=\sqrt{u_{10}^{2}+v_{10}^{2}+s^{2}} .
$$

The linearisation and cost function gradient (adjoint) of the modified wind speed are then always well defined and $s$ (taken to be $0.1 \mathrm{~ms}^{-1}$ ) can be physically justified as a representation of sub-grid scale wind variability. 


\subsection{Minimisation}

The minimisation method in Met Office 4D-Var is the double inner-loop descent algorithm, where at each iteration a descent direction is determined using the conjugate gradient method. The number of iterations in operational 4D-Var is currently fixed at 40 with a non-linear iteration every 10 th cycle.

For non-linear iterations (including the $1^{\text {st }}$ iteration):

- The wind speed calculation is updated using the full non-linear operator Eq. (8)Error! Reference source not found.

- The linearisation state coefficients $u_{10 \mathrm{c}}, v_{10 \mathrm{c}}, w s_{10 \mathrm{c}}$ and gradients are updated and saved (for use in subsequent linearisations and the adjoint)

$$
\begin{aligned}
& u_{10 \mathrm{c}}=u_{10}, \\
& v_{10 \mathrm{c}}=v_{10}, \\
& w S_{10 \mathrm{c}}=w S=\sqrt{{u_{10 \mathrm{c}}}^{2}+v_{10 \mathrm{c}}{ }^{2}+s^{2}} .
\end{aligned}
$$

At inner, quadratic iterations:

- The wind speed is approximated using the linear operator Eq. (7)Error! Reference source not found. - the linearisation of the wind speed calculation about the updateable linearisation state:

$$
w S_{\text {lin }}=w S_{10 \mathrm{c}}+\left(\frac{u_{10 \mathrm{c}}}{w S_{10 \mathrm{c}}}\right)\left(u_{10}-u_{10 \mathrm{c}}\right)+\left(\frac{v_{10 \mathrm{c}}}{w S_{10 \mathrm{c}}}\right)\left(v_{10}-v_{10 \mathrm{c}}\right) .
$$

The linearisation state coefficients are those saved from an earlier non-linear iteration.

\subsection{Gradient Calculation}

In variational analysis we are trying to find the values of the control variables which

minimise the penalty function $J$. The variational descent minimisation requires the gradient of the cost function - the partial derivatives of $J$ with respect to the control variables known as 
the adjoint. In this case the control variables are $u_{10}, v_{10}$, and the active variable which depends on these is the wind speed ws. Let the penalty be defined as

$$
J=0.5 * \frac{\left(w s-w s_{0}\right)^{2}}{\sigma_{\mathrm{o}}^{2}} .
$$

Then the partial derivatives are (using Eq. (6)Error! Reference source not found.)

$$
\begin{aligned}
\frac{\partial J}{\partial u_{10}} & =\frac{\partial J}{\partial w s} \frac{\partial w s}{\partial u_{10}} & \frac{\partial J}{\partial v_{10}} & =\frac{\partial J}{\partial w s} \frac{\partial w s}{\partial v_{10}} \\
& =\frac{\partial J}{\partial w s}\left(\frac{u_{10}}{w s}\right), & & =\frac{\partial J}{\partial w s}\left(\frac{v_{10}}{w s}\right),
\end{aligned}
$$

where

$$
\frac{\partial J}{\partial w s}=\frac{w s-w s_{0}}{\sigma_{\mathrm{o}}^{2}}
$$

Therefore the gradient with respect to the wind speed is

$$
\hat{w}=\frac{w s_{10 c}-w s_{0}}{\sigma_{o}^{2}}
$$

and the adjoint gradient calculations are

$$
\hat{u}=\hat{w}\left(\frac{u_{10 c}}{w S_{10 c}}\right), \quad \hat{v}=\hat{w}\left(\frac{v_{10 c}}{w S_{10 c}}\right) .
$$

\section{References}

Barré HM, Duesmann B, Kerr YH. 2008. SMOS: The mission and the system. IEEE Trans.

Geosci. Remote Sens. 46(3): 587-593.

Bentamy A, Croize-Fillon D, Perigaud C. 2008. Characterization of ASCAT measurements based on buoy and QuikSCAT wind vector observations. Ocean Sci. 4: 265-274. 
Cameron J, Bell W. 2016. 'The testing and planned implementation of variational bias correction (VarBC) at the Met Office'. In Proceedings of the International TOVS Study Conferences (ITSC)-XX, Wisconsin, USA, October 2015.

Candy B, English SJ, Keogh SJ. 2009. A Comparison of the Impact of QuikScat and WindSat Wind Vector Products on Met Office Analyses and Forecasts. IEEE Trans. Geosci. Remote Sens. 47(6): 1632-1640.

Clayton AM, Lorenc AC, Barker DM. 2013. Operational implementation of a hybrid ensemble/4D-Var global data assimilation system at the Met Office. Q. J. R. Meteorol. Soc. 139: 1445-1461. DOI: 10.1002/qj.2054

Cotton J. 2013. 'The impact of ASCAT winds from Metop-B and a new scatterometer thinning scheme`. Forecasting Research Technical Report No. 580. Met Office: Exeter, UK.

Davies T, Cullen MJP, Malcolm AJ, Mawson MH, Staniforth A, White AA, Wood N. 2005. A new dynamical core for the Met Office's global and regional modelling of the atmosphere. Q. J. R. Met. Soc. 131: 1759-1782.

Desroziers G, Berre L, Chapnik B, Poli P. 2005. Diagnosis of observation, background and analysis-error statistics in observation space. Q. J. R. Meteorol. Soc. 131: 3385-3396.

Heming J. 2016. Met Office Unified Model Tropical Cyclone Performance Following Major Changes to the Initialization Scheme and a Model Upgrade. Wea. Forecast. 31: 1433-1449. DOI: 10.1175/WAF-D-16-0040.1. 
Heming J. 2017. Tropical cyclone tracking and verification techniques for Met Office numerical weather prediction models. Met. Apps. 24: 1-8. DOI: 10.1002/met.1599

Ingleby N, Lorenc A. 1993. Bayesian quality control using multivariate normal distributions. Q. J. R. Meteorol. Soc. 119: 1195-1225.

Kaleschke L, Tian-Kunze X, Maaß N, Mäkynen M, Drusch M. 2012. Sea ice thickness retrieval from SMOS brightness temperatures during the Arctic freeze-up period. Geophys. Res. Lett. 39. DOI: 10.1029/2012GL050916.

Keogh SJ, Candy B. 2008. `The Impact of MetOp-A ASCAT ocean surface wind vectors on Met Office Global Model Forecasts`. Forecasting Research Technical Report No. 511. Met Office: Exeter, UK.

Kerr YH, Waldteufel P, Wigneron JP, Martinuzzi J, Font J, Berger M. 2001. Soil moisture retrieval from space: The Soil Moisture and Ocean Salinity (SMOS) mission. IEEE Trans. Geosci. Remote Sens. 39: 1729-1735.

Knapp KR, Kruk MC, Levinson DH, Diamond HJ, Neumann CJ. 2010. The International Best Track Archive for Climate Stewardship (IBTrACS): Unifying tropical cyclone best track data. Bull. Amer. Meteor. Soc. 91: 363-376. DOI: 10.1175/2009BAMS2755.1

Lorenc A, Hammon O. 1988. Objective quality control of observations using Bayesian methods. Theory and a practical implementation. Q. J. R. Meteorol. Soc. 114: 515-543. 
Meissner T, Ricciardulli L, Wentz FJ. 2017. Capability of the SMAP Mission to Measure Ocean Surface Winds in Storms. Bull. Amer. Meteor. Soc. 0. DOI: 10.1175/BAMS-D-160052.1.

McMullan KD, Brown MA, Martín-Neira M, Rits W, Ekholm S, Marti J, Lemanczyk J. 2008. SMOS: The payload. IEEE Trans. Geosci. Remote Sens. 46: 594-605.

Neumann CJ. 1972. An alternative to the HURRAN tropical cyclone forecast system. Mon. Wea. Rev. 100: 245-255. DOI: 10.1175/1520-0493.

Oliva R, Daganzo E, Richaume P, Kerr Y, Cabot F, Soldo Y, Anterrieu E, Reul N, Gutierrez A, Barbosa J, Lopes G. 2016. Status of Radio Frequency Interference (RFI) in the 1400-1427 MHz passive band based on six years of SMOS mission. Remote Sens. Environ. 180: 64-75.

Portabella M, Stoffelen A. 2001. Rain detection and quality control of SeaWinds. Journal Atmos. Ocean. Tech. 18: 1171-1183.

Rawlins F, Ballard SP, Bovis KJ, Clayton AM, Li D, Inverarity GW, Lorenc AC, Payne TJ. 2007. The Met Office global four-dimensional variational data assimilation scheme. Q. J. $R$. Meteorol. Soc. 133: 347-362.

Reul N, Tenerelli J, Chapron B, Vandemark D, Quilfen Y, Kerr Y. 2012. SMOS satellite Lband radiometer: A new capability for ocean surface remote sensing in hurricanes. $J$.

Geophys. Res. 117: DOI: 10.1029/2011JC007474. 
Reul N, Chapron B, Zabolotskikh E, Donlon C, Quilfen Y, Guimbard S, Piolle JF. 2016. A revised L-band radio-brightness sensitivity to extreme winds under tropical cyclones: The 5 year SMOS-Storm database. Remote Sens. Environ. 180: 274-291.

Reul N, Chapron B, Zabolotskikh E, Donlon C, Mouche A, Tenerelli J, Collard F, Piolle J-F, Fore A, Yueh S, Cotton J, Francis P, Quilfen Y, Kudryavtsev V. 2017. A new generation of Tropical Cyclone Size measurements from space. Bull. Amer. Meteor. Soc. 0:

10.1175/BAMS-D-15-00291.1.

Ridley J, Ballard S. 2000. 'Impact trials for the assimilation of SSM/I wind speeds in the global NWP model '. Forecasting Research Technical Report No. 275. Met Office: Exeter, UK.

Soisuvarn S, Jelenak Z, Chang PS, Alsweiss SO, Zhu Q. 2013. CMOD5. H - A high wind geophysical model function for C-band vertically polarized satellite scatterometer measurements. IEEE Trans. Geosci. Remote Sens. 51: 3744-3760.

Stoffelen A, Vogelzang J. 2015. 'Wind bias correction guide`. Technical report NWPSAFKN-UD-007 v1.2. NWP SAF. Available from http://nwpsaf.eu.

Walters D, Wood N, Vosper S, Milton S. 2014. `ENDGame: A new dynamical core for seamless atmospheric prediction'. Met Office documentation can be consulted at http://www.metoffice.gov.uk/binaries/content/assets/mohippo/pdf/s/h/endgamegovsci_v2.0.p df 
Weston P. 2014. `The statistical significance of assimilation trial results: case study on SA package trials for PS34: Satellite Applications Technical Memo No. 22. Met Office: Exeter, UK.

Weston P, Bell W, Eyre J. 2014. Accounting for correlated error in the assimilation of highresolution sounder data. Q. J. R. Meteorol. Soc. 140: 2420-2429. DOI: 10.1002/qj.2306

Yin X, Boutin J, Martin N, Spurgeon P, Vergely J-L, Gaillard F. 2014. Errors in SMOS sea surface salinity and their dependency on a priori wind speed. Remote Sens. Environ. 146: $159-171$.

Table 1. Departure statistics partitioned by each quality flag, for un-flagged data, and after applying the background check. Data from 1-10 August 2014.

\begin{tabular}{lccccc}
\hline Data selection & Number & $\begin{array}{r}\% \\
\left(\mathrm{v}>10 \mathrm{~ms}^{-1}\right)\end{array}$ & $\begin{array}{c}\text { Mean } \\
\mathrm{O}-\mathrm{B} \mathrm{ms}^{-1}\end{array}$ & $\begin{array}{c}\text { STDV } \\
\mathrm{O}-\mathrm{B} \mathrm{ms} \mathrm{m}^{-1}\end{array}$ & $\begin{array}{c}\text { Correlation } \\
\mathrm{R}\end{array}$ \\
\hline All data & & & & & \\
& 10135124 & 100.0 & 0.12 & 2.83 & 0.80 \\
Un-flagged & 8739375 & $86.2(88.8)$ & 0.08 & 2.65 & 0.82 \\
& & & & & \\
Coast/ Flag 1 & 291216 & $2.9(1.3)$ & 0.31 & 3.69 & 0.57 \\
SSS/ Flag 4 & 189020 & $1.9(0.7)$ & 0.53 & 3.41 & 0.59 \\
SST/ Flag 5 & 329819 & $3.3(6.7)$ & 0.13 & 4.35 & 0.66 \\
Mod RFI/ Flag 7 & 372949 & $3.7(1.5)$ & 0.07 & 3.22 & 0.60 \\
High RFI/ Flag 8 & 212162 & $2.1(0.9)$ & 0.28 & 3.61 & 0.59 \\
BTvar/ Flag 9 & 92475 & $0.9(0.3)$ & 2.37 & 4.75 & 0.44 \\
& & & & & \\
Un-flagged+bgcheck & 8729924 & $86.1(88.8)$ & 0.06 & 2.56 & 0.83 \\
\hline
\end{tabular}


Table 2. SMOS and ASCAT O-B departure statistics for different model wind speed bins.

Data from August 2014 after applying quality flag checks (both) and background check (SMOS only)

\begin{tabular}{llllll}
\hline Model speed & Sensor & Number & Mean $\mathrm{ms}^{-1}$ & STDV $\mathrm{ms}^{-1}$ & RMS ms \\
\hline \multirow{2}{*}{$15 \mathrm{~ms}^{-1}$} & ASCAT-B & 13639952 & 0.28 & 1.16 & 1.20 \\
& SMOS & 25725754 & 0.02 & 2.44 & 2.51 \\
\hline \multirow{2}{*}{$15-20 \mathrm{~ms}^{-1}$} & ASCAT-B & 588369 & -0.32 & 1.12 & 1.18 \\
& SMOS & 1416451 & 0.62 & 2.60 & 2.67 \\
\hline \multirow{2}{*}{$20-25 \mathrm{~ms}^{-1}$} & ASCAT-B & 47328 & -1.09 & 1.28 & 1.70 \\
& SMOS & 134074 & 0.67 & 2.48 & 2.57 \\
\hline \multirow{2}{*}{$25-30 \mathrm{~ms}^{-1}$} & ASCAT-B & 2164 & -1.79 & 1.78 & 2.54 \\
& SMOS & 6837 & 1.65 & 2.39 & 2.94 \\
\hline \multirow{2}{*}{$30-35 \mathrm{~ms}^{-1}$} & ASCAT-B & 97 & -4.04 & 1.63 & 4.40 \\
& SMOS & 115 & 2.21 & 2.93 & 3.70 \\
\hline \multirow{2}{*}{$35 \mathrm{~ms}^{-1}$} & ASCAT-B & 8 & -8.56 & 1.07 & 8.67 \\
& SMOS & 13 & 0.34 & 1.88 & 2.06 \\
\hline
\end{tabular}

Table 3. List of data types used in the control experiments. Details of the satellites and instruments can be found in the OSCAR space directory: https://www.wmo-

\section{sat.info/oscar/spacecapabilities}

\begin{tabular}{ll}
\hline Observation type & Details \\
\hline Non-satellite & Aircraft, radiosonde, wind profilers, surface \\
Hyperspectral infrared sounders & AIRS, IASI, CrIS \\
Microwave sounders and imagers & ATOVS, ATMS, AMSR-2, SSMIS \\
Atmospheric Motion Vectors & Meteosat-7/10, MTSAT, GOES-13/15, AVHRR, MODIS, LeoGeo \\
Scatterometer and radiometer surface winds & ASCAT-A/B, WindSat, RapidScat* \\
GNSS Radio Occultation & \\
Geostationary clear sky radiances & GOES-13/15, Meteosat-7/10 \\
Ground based GNSS & \\
Aerosol Optical Depth & MODIS \\
\hline RapidScat data available for the 2015 trial period only
\end{tabular}


Table 4. Experiment list and NWP Index scores for the August-October 2014 period.

\begin{tabular}{lcccc}
\hline Experiment & TCCPIS used & $\begin{array}{c}\text { NWP Index vs. } \\
\text { Observations }\end{array}$ & $\begin{array}{c}\text { NWP Index vs. } \\
\text { Analyses }\end{array}$ & $\begin{array}{c}\text { NWP Index vs. } \\
\text { ECMWF Analyses }\end{array}$ \\
\hline Control+TCP & Yes & & & \\
SMOS+TCP & Yes & $+0.02(0.02 \%)$ & $+0.06(0.05 \%)$ & $+0.05(0.05 \%)$ \\
ControlNoTCP & No & & & \\
SMOSNoTCP* & No & $+0.05(0.05 \%)$ & $+0.11(0.09 \%)$ & $+0.07(0.08 \%)$ \\
StretchNoTCP & No & $+0.19(0.19 \%)$ & $+0.35(0.28 \%)$ & $+0.13(0.12 \%)$ \\
*Trial stopped after 31 days. & & &
\end{tabular}

Table 5. TC track and intensity verification for the SMOS trials versus control. Changes in mean relative vorticity (RV) at $850 \mathrm{hPa}, 10 \mathrm{~m}$ wind, and minimum mean sea level pressure (MSLP) are given versus the respective control experiments. Also shown are the changes in mean absolute error (MAE), mean direct positional error (DPE), and track skill compared to the control experiment (MAE/DPE verified against best-track and track skill against CLIPER). All forecasts are averaged from $\mathrm{T}+12$ to $\mathrm{T}+144$ at 12-hour intervals.

\begin{tabular}{lllcccccc}
\hline Experiment & Range & $\begin{array}{c}\text { RV } \\
(\%)\end{array}$ & $\begin{array}{c}\text { Wind } \\
(\%)\end{array}$ & $\begin{array}{c}\text { MSLP } \\
(\mathrm{mb})\end{array}$ & $\begin{array}{c}\text { Wind } \\
\text { MAE (knots) }\end{array}$ & $\begin{array}{c}\text { MSLP } \\
\text { MAE (mb) }\end{array}$ & $\begin{array}{c}\text { DPE } \\
(\%)\end{array}$ & $\begin{array}{c}\text { Track Skill } \\
(\%)\end{array}$ \\
\hline SMOS+TCP & T+0 & -1.7 & -0.8 & +0.5 & +0.4 & +0.3 & -2.6 & -1.1 \\
& All forecasts & -0.7 & -0.4 & +0.2 & +0.1 & +0.1 & -1.1 & \\
& & & & & & & & \\
\multirow{5}{*}{ StretchNoTCP } & T+0 & +4.5 & +2.1 & -0.7 & -0.8 & -0.4 & -0.9 & -0.6 \\
& All forecasts & +2.0 & +1.0 & -0.4 & -0.4 & -0.2 & +2.1 & \\
\hline
\end{tabular}


Table 6. TC track and intensity verification for SMOS experiment StretchNoTCP versus ControlNoTCP. The notation used is the same as for Table 5.

\begin{tabular}{|c|c|c|c|c|c|c|c|c|}
\hline Storm & Range & $\begin{array}{l}\mathrm{RV} \\
(\%)\end{array}$ & $\begin{array}{l}\text { Wind } \\
(\%)\end{array}$ & $\begin{array}{l}\text { MSLP } \\
(\mathrm{mb})\end{array}$ & $\begin{array}{c}\text { Wind } \\
\text { MAE (knots) }\end{array}$ & $\begin{array}{c}\text { MSLP } \\
\text { MAE (mb) }\end{array}$ & $\begin{array}{l}\text { DPE } \\
(\%)\end{array}$ & $\begin{array}{c}\text { Track Skill } \\
(\%)\end{array}$ \\
\hline \multirow[t]{2}{*}{ All } & $\mathrm{T}+0$ & +6.0 & +2.9 & -0.9 & -1.0 & -0.6 & -1.9 & \\
\hline & All forecasts & +1.3 & +0.7 & -0.3 & -0.2 & -0.2 & +1.3 & -1.5 \\
\hline \multirow[t]{2}{*}{ Ignacio } & $\mathrm{T}+0$ & +5.1 & +1.6 & -0.9 & -0.6 & -0.5 & -8.9 & \\
\hline & All forecasts & +2.2 & +0.4 & -0.1 & -0.2 & -0.1 & +3.6 & -0.8 \\
\hline \multirow[t]{2}{*}{ Jimena } & $\mathrm{T}+0$ & +7.9 & +4.0 & -1.2 & -1.6 & -1.0 & +3.1 & \\
\hline & All forecasts & +2.9 & +1.0 & -0.4 & -0.4 & -0.3 & +3.2 & -2.3 \\
\hline \multirow[t]{2}{*}{ Kilo } & $\mathrm{T}+0$ & +8.2 & +3.9 & -1.9 & -1.5 & -1.0 & +8.9 & \\
\hline & All forecasts & -0.1 & +0.3 & -0.4 & -0.1 & 0.0 & +1.8 & -2.5 \\
\hline
\end{tabular}

\section{List of Figures}

Figure 1. Two-dimensional histograms of SMOS wind speed versus model background wind speed for; a) all data, b) flagged data only, c) all data after quality flag checks, and d) additionally applying the background check. Data is from 1-10 August 2014. The colour scale represents the number of data points in each 2-D wind speed bin. A dashed line shows the mean fit about the $1: 1$ line.

Figure 2. SMOS (solid) and ASCAT-B $25 \mathrm{~km}$ (dash) mean O-B speed as a function of model background wind speed. Error bars represent $+/-1$ standard deviation. Data from August 2014 after applying quality flag (both) and background check (SMOS only). Only bins containing more than 10 observations are plotted. 
Figure 3. Maps showing mean and standard deviation speed bias for SMOS data in August 2014. The plots in the left column (a, c) show all data, the plots in the right column (b, d) are after applying the quality flag and background checks.

Figure 4. Mean (dashed) and standard deviation (solid-circles) O-B speed as a function of scan or swath position. Also plotted are the numbers of observations in each distance bin (histogram). SMOS data are from August 2014 after applying the quality flag and background checks. The scan position is converted from a dimensionless measure of the across-track distance.

Figure 5. a) Spatial observation error covariances and b) spatial error correlations as a function of separation distance for SMOS wind speeds above $12 \mathrm{~ms}^{-1}$ after applying the quality flag and background checks. Data for 7 days from 0000 UTC 22 August 2014 to 1800 UTC 28 August 2014.

Figure 6. Distribution of assimilated SMOS wind speeds for August 2014 for experiment a) SMOS+TCP, b) StretchNoTCP.

Figure 7. The difference in the mean zonal wind analysis at $10 \mathrm{~m}$ between experiments StretchNoTCP and ControlNoTCP.

Figure 8. The change in geopotential height RMS forecast errors at $1000 \mathrm{hPa}$ for day 2 forecasts for experiment StretchNoTCP minus ControlNoTCP. 
Figure 9. Percentage change in forecast RMS error (trial minus control) for experiment SMOS+TCP compared with Control+TCP. Verification against observations (left), own analyses (centre), and independent ECMWF analyses (right). Upward triangles indicate a positive impact (reduction in error) and downward triangles indicate a negative impact (increase in error). The size of the triangles is scaled to the size of the RMS change with a maximum of 5\% filling the square box. Triangles with dark outlines show a significant impact at the 95\% level (Wilcoxon signed-rank test).

Figure 10. As Figure 9 but for experiment StretchNoTCP compared with ControlNoTCP for Aug-Oct 2014 season.

Figure 11. TC mean relative vorticity at $850 \mathrm{hPa}$ for the controls (solid lines) and SMOS trials (dashed). The experiments with the TCCPIS active are shown by triangle markers and experiments without TCCPIS by square markers.

Figure 12. Mean a) TC central pressure bias, and b) $10 \mathrm{~m}$ wind bias for the same experiments as in Figure 11. Verification of TC intensity is versus best-track data.

Figure 13. Mean direct positional error (solid) and track skill (dashed) for experiments (a) SMOS+TCP and (b) StretchNoTCP. The histogram shows the number of forecasts at each lead time. Verification of TC track is versus best-track data.

Figure 14. Same caption as Figure 9 but for experiment StretchNoTCP compared with ControlNoTCP for the Aug-Sep 2015 season. 
Figure 15. Analysed (markers) and forecast (lines) central pressures from the SMOS experiment (blue-circles) compared with the control (green-diamonds) for Hurricane Kilo. Observed pressures (thick grey line) are from best-track. The triangles on x-axis show assimilation cycles that have a SMOS intercept of the storm centre.

Figure 16. SMOS observations and model data for 1800 UTC cycle on 29 August 2015. a) Background wind speed, b) SMOS wind speeds for intercept at 1718 UTC, c) O-B wind speed for data after quality control, d) analysis increment in wind speed.

Figure 17. Same caption as Figure 16 but for 0600 UTC cycle on 5 September 2015. SMOS intercept of the storm is at 0650 UTC. 


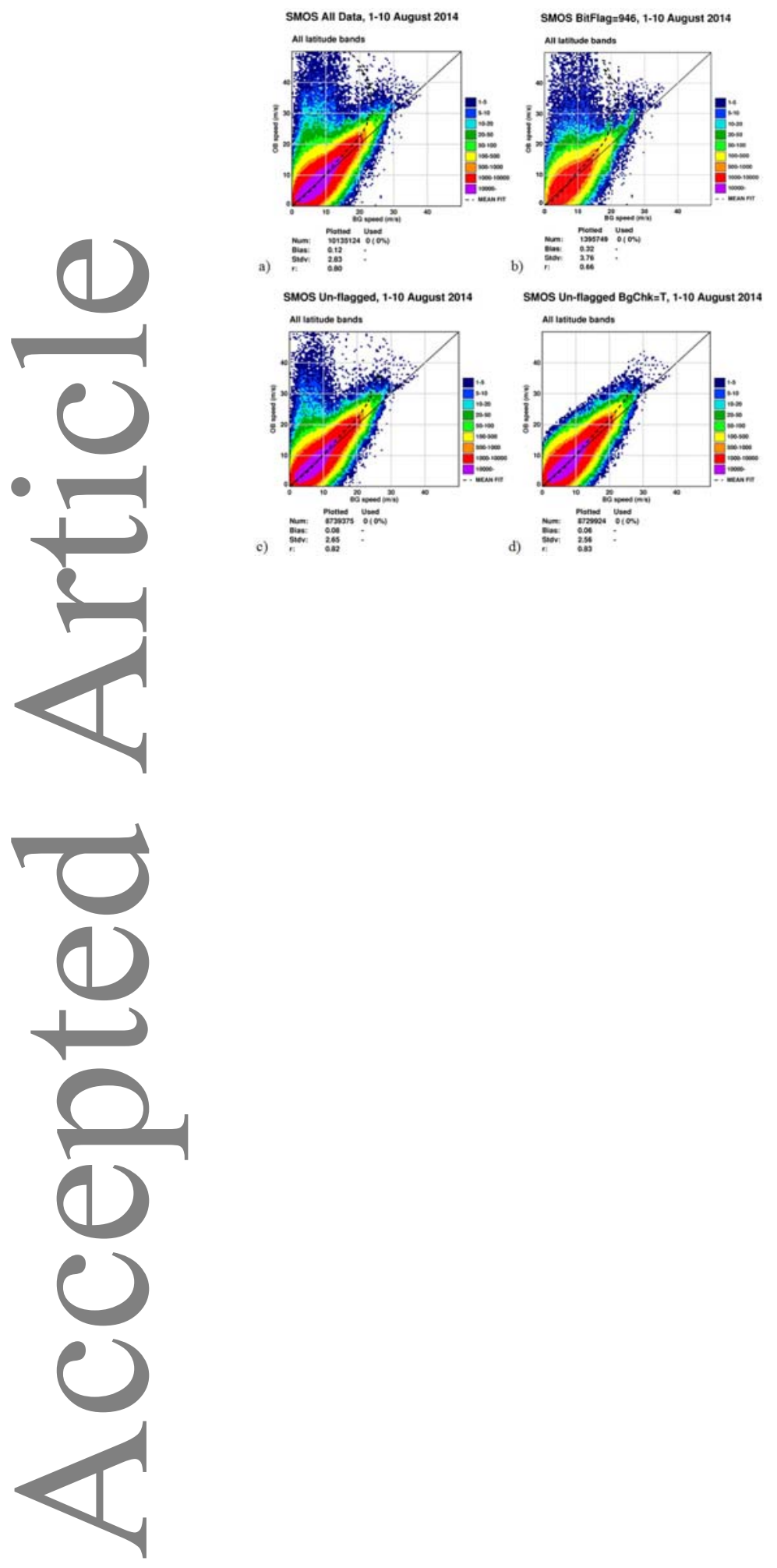




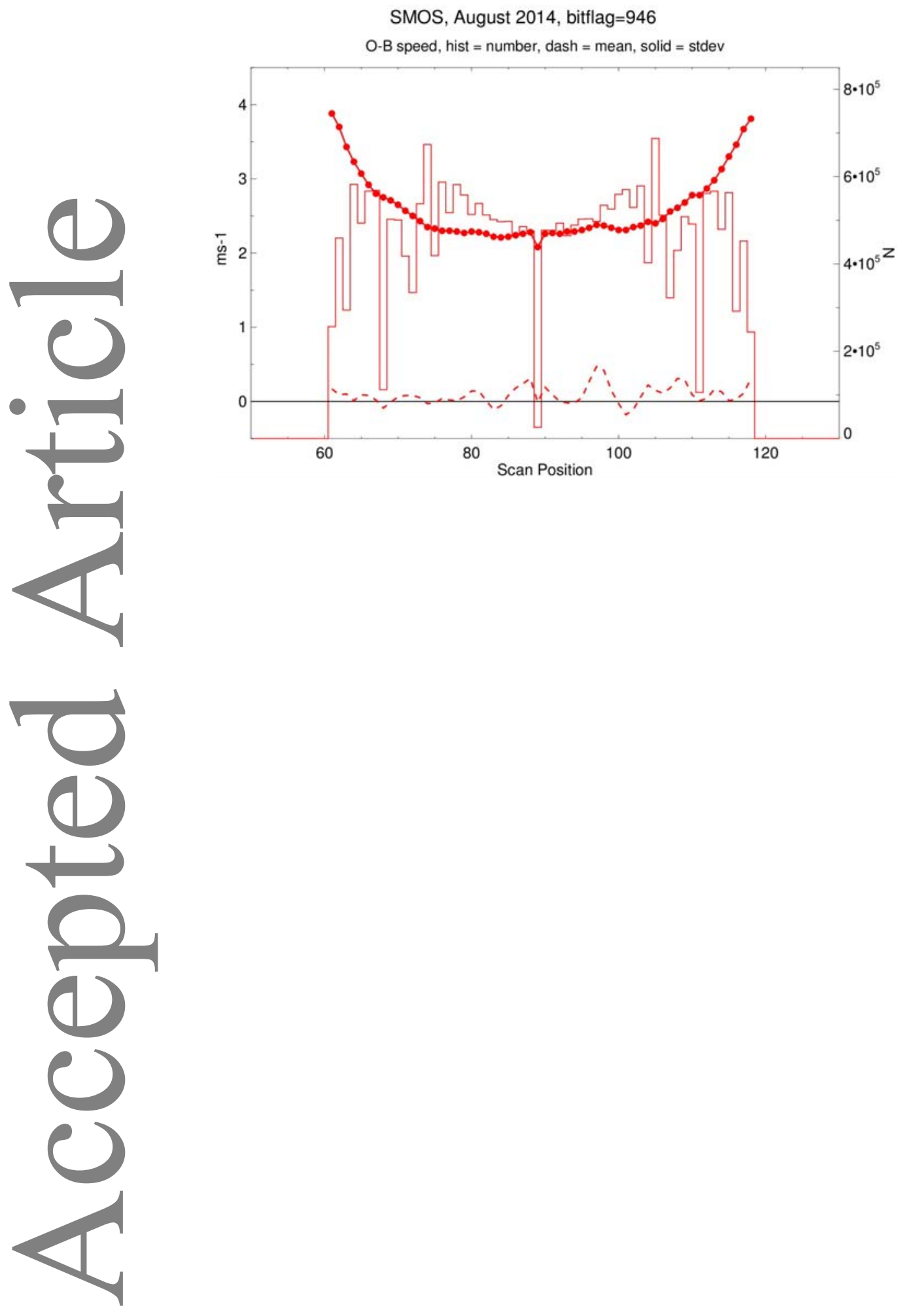

This article is protected by copyright. All rights reserved. 

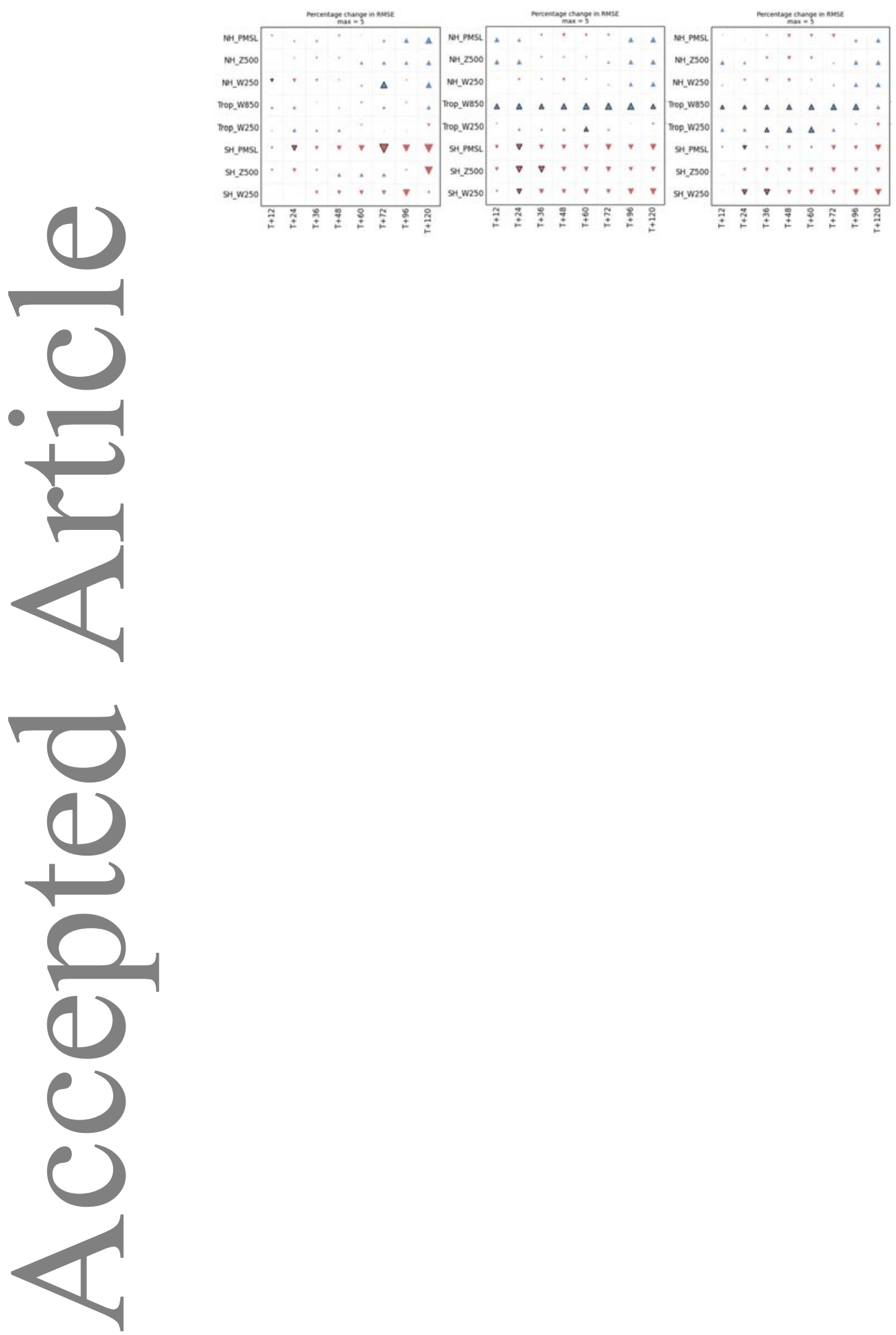

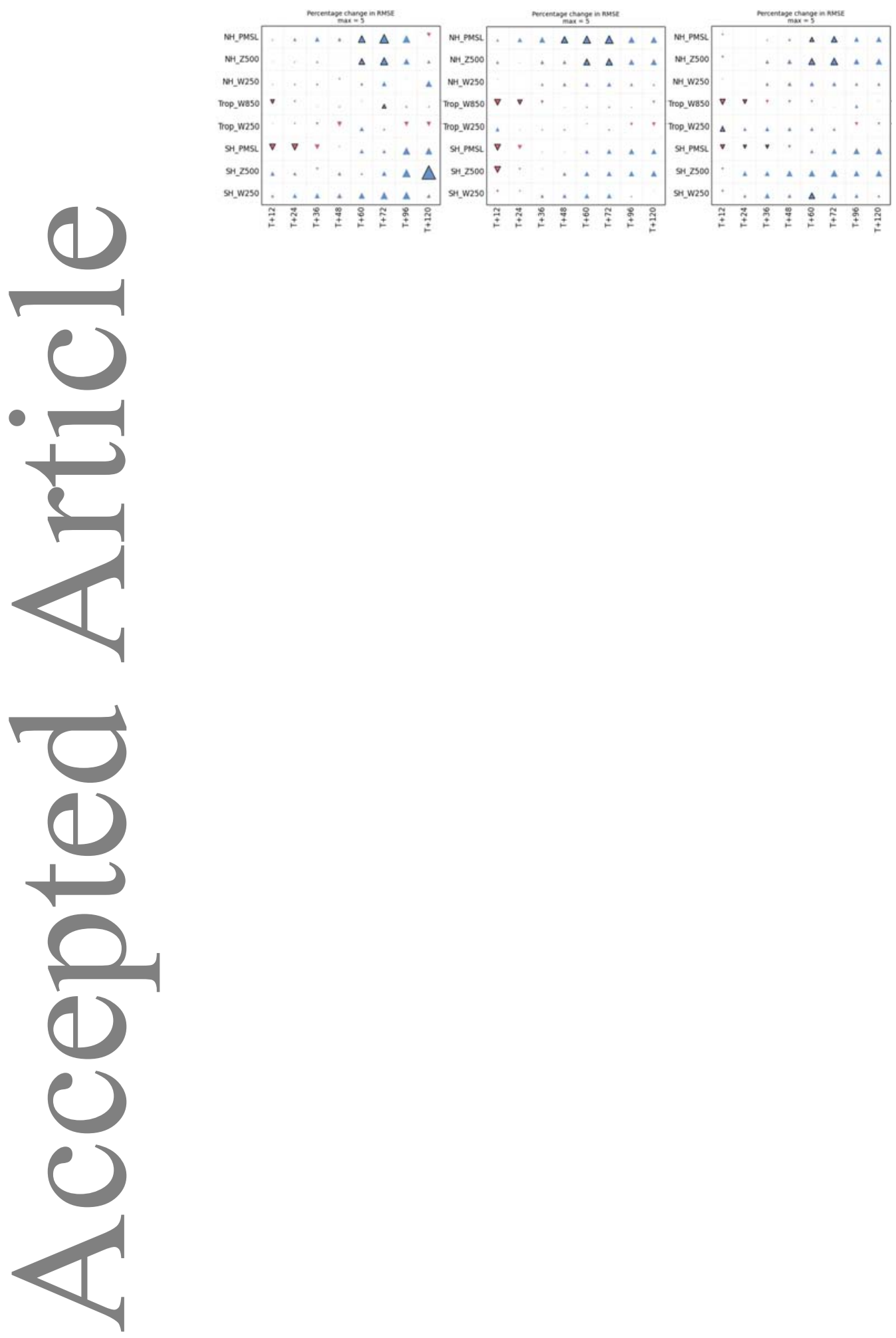


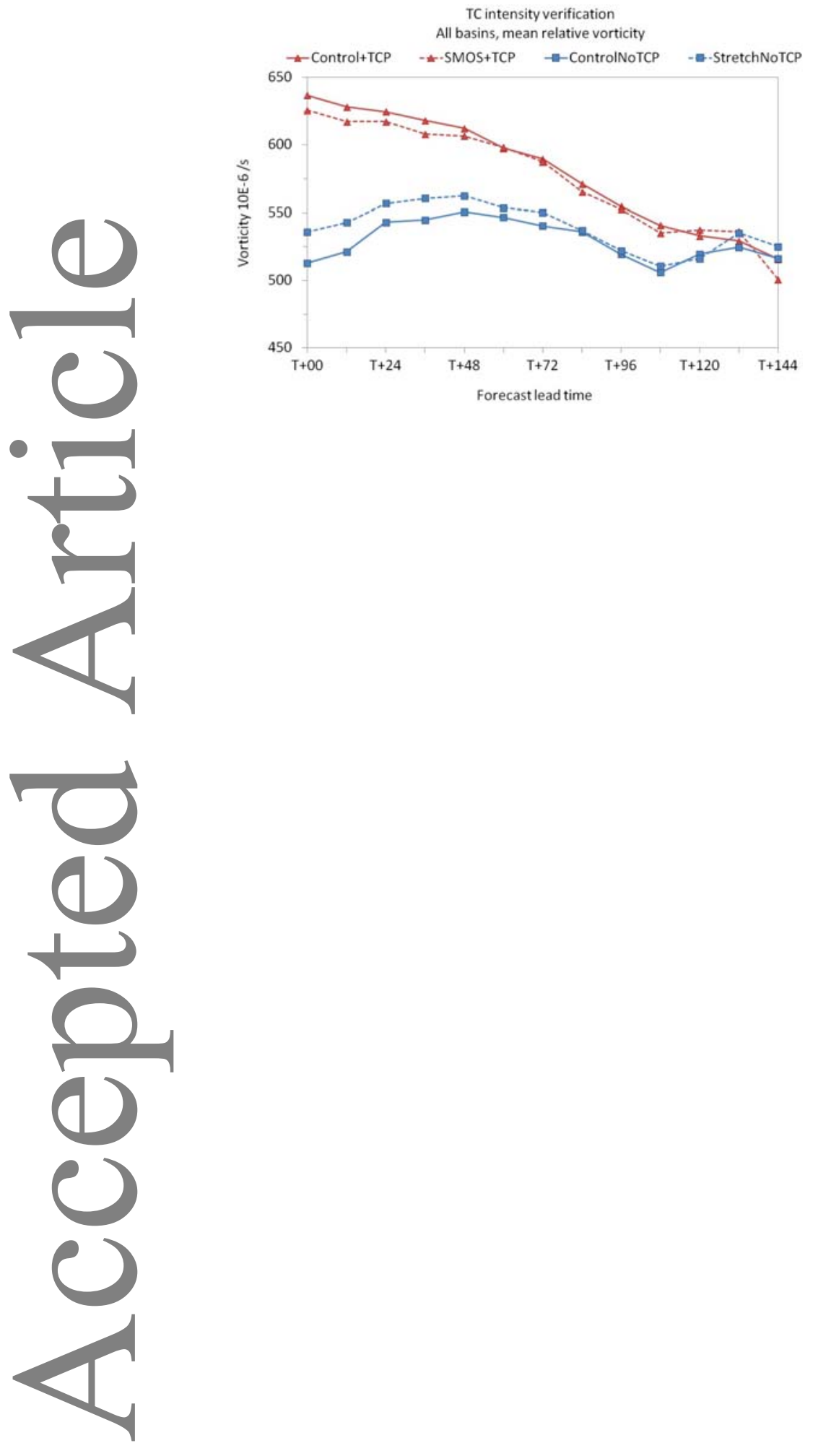

This article is protected by copyright. All rights reserved. 


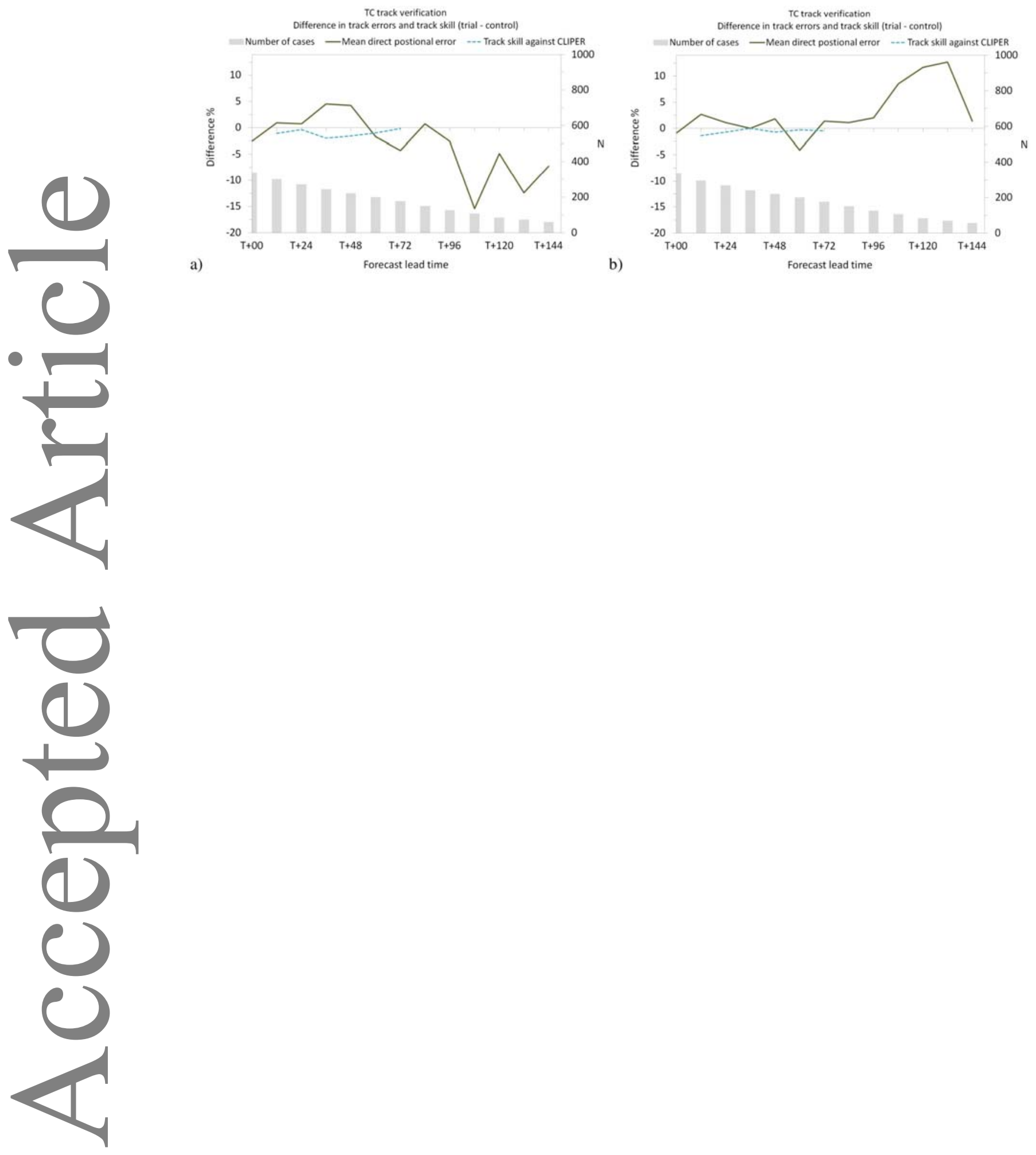

This article is protected by copyright. All rights reserved. 


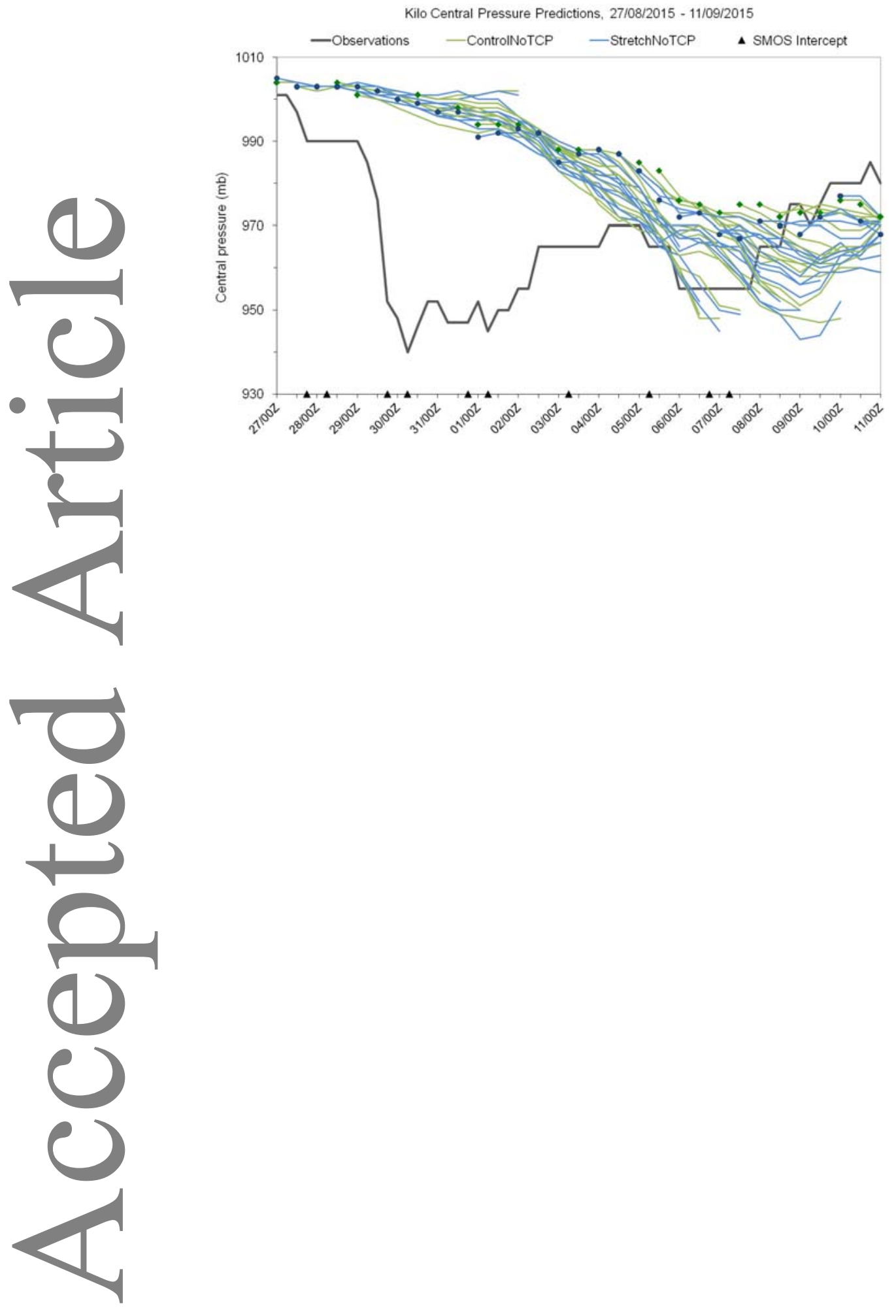

This article is protected by copyright. All rights reserved. 


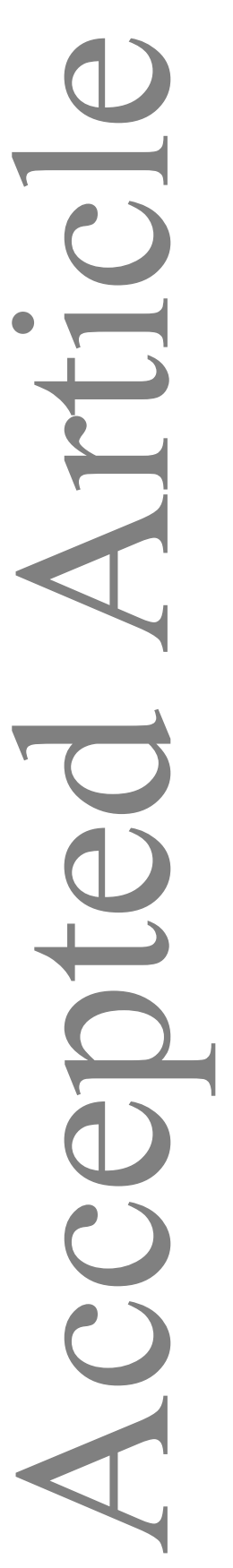

a)
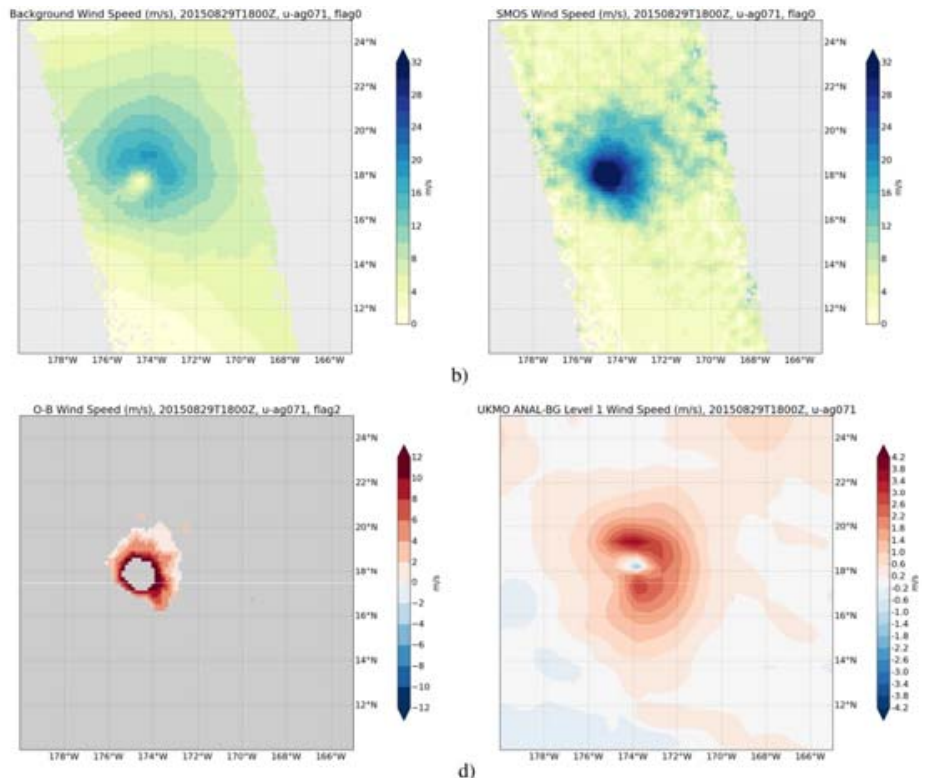

c)

d)

$$
\text { . }
$$


